\title{
Role for cFMS in maintaining alternative macrophage polarization in SIV infection: implications for HIV neuropathogenesis
}

\author{
Lindsey Gerngross, Gabrielle Lehmicke, Aghilas Belkadi and Tracy Fischer
}

\begin{abstract}
Background: Macrophage-colony stimulating factor (M-CSF) has been implicated in HIV neuropathogenesis through its ability to modulate activation of macrophages (MФs) and microglia, as well as enhance the susceptibility of these cells to infection and promote virus production. We have recently reported that MФs accumulating perivascularly and within nodular lesions in archival brain tissue of simian immunodeficiency virus (SIV)-infected rhesus macaques with encephalitis (SIVE) express M-CSF. In contrast, IL-34, which shares the same receptor, cFMS, was observed more often in parenchymal cells.

Methods: Frontal white and grey matter from non-infected and SIV-infected rhesus macaques with and without SIVE were examined by single- and double-label immunohistochemistry for M-CSF, IL-34, and CD163 expression. Primary rhesus macaque and human peripheral blood mononuclear cells were cultured with and without $2.5 \mathrm{ng} /$ $\mathrm{ml}$ M-CSF or IL-34 alone and with $470 \mathrm{nM}$ or $4.7 \mu \mathrm{M}$ of GW2580, a receptor tyrosine kinase inhibitor with high specificity for cFMS. After $24 \mathrm{~h}$, cells were analyzed by flow cytometry to examine the effect of these cytokines on promoting an $\mathrm{M} 2$ monocyte/MФ phenotype.
\end{abstract}

Results: Here, we demonstrate that in SIVE brain, accumulating M-CSF ${ }^{+}$MФs are also CD163 ${ }^{+}$, while IL-34 does not appear to co-localize significantly with CD163 in the parenchyma. We further demonstrate that M-CSF and IL-34 are expressed by neurons in normal brain but are altered in SIV and SIVE. Through in vitro studies, we show that M-CSF and IL-34 upregulate CD163, a marker for type 2 activation of MDs (M2), by primary monocytes, which is attenuated by the addition of GW2580.

Conclusions: Together, these data suggest that both cFMS ligands may promote and/or prolong M2 activation of MФs and microglia in brains of SIV-infected animals with encephalitis. As such, cFMS signaling may be an attractive target for eliminating long-lived $M \Phi$ reservoirs of HIV infection in brain, as well as other tissues.

Keywords: M-CSF, IL-34, CFMS, M2, Macrophage, Alternative activation, CD163 HIV, SIV, Encephalitis

\section{Background}

Microglia and macrophages (MФs) found within compartments associated with the central nervous system (CNS), such as perivascular $М Ф s$, are essential to fighting off foreign pathogens, as well as maintaining CNS homeostasis. Injury to the CNS results in rapid activation of microglia and CNS-associated MФs, which upregulate numerous cell-surface and soluble factors that trigger or amplify innate and acquired immune responses. The type, degree,

\footnotetext{
* Correspondence: tlfsmith@temple.edu

Department of Neuroscience, Center for Neurovirology, Temple University School of Medicine, MERB, Room 748, Philadelphia, PA 19140, USA
}

and length of the microglial/M $\Phi$ response to injury can determine whether they are neuroprotective or contribute to neurodegeneration (for review, see Amor et al. [1]).

In addition to their pro-inflammatory functions and role in coordinating an adaptive immune response, tissue $M \Phi s$, including microglia, are involved in resolving inflammation and tissue remodeling and repair. To perform these varied functions, $М \Phi$ activation is considerably plastic and heterogeneous, broadly classified into two primary subclasses of classical (M1) and alternative (M2) activation, based on distinct functional and phenotypic characteristics (for review, see Liu et al. 
and Wang et al. [2,3]). Classically activated, proinflammatory M1 MФs secrete interleukin (IL)-12 and support $\mathrm{T}$ helper $\left(\mathrm{T}_{\mathrm{H}}\right) 1$ cell responses [4]. In contrast, alternatively activated, anti-inflammatory M2 MФs secrete IL-10, suppress $T_{H} 1$ function, and stimulate $T_{H} 2$ cell production [5,6]. A balance between classical and alternative activation is necessary for appropriate immune function and in a healthy immune response, MФs are believed to rapidly shift from one activation state to another in response to external stimuli [7].

Although M2 MФs are often considered 'favorable' due to their role in resolving inflammation, inducing tolerance, and promoting wound healing $[6,8,9]$, an increase in the frequency of M2-polarized MФs is believed to have injurious results associated with their transcriptional output in many chronic inflammatory conditions, including rheumatoid arthritis, atherosclerosis, and obesity [10-13]. In addition, extensive or prolonged M2 polarization may contribute to disease pathogenesis by weakening host immunity. For example, soluble factors produced by tumor-associated MФs, which are reported to express markers consistent with M2-polarization [14], contribute to the impaired immune surveillance seen within the glioma microenvironment [15]. In neuroinflammatory disease, alternatively activated MФs may be a continued source of reactive oxygen species (ROS) in the brain, which are necessary for conversion to M2 activation [16].

Many individuals with human immunodeficiency virus (HIV) infection develop varying degrees of cognitive impairment, collectively termed HIV-associated neurocognitive disorders (HAND). Although the pathogenesis of HAND is not completely understood, activated microglia and infiltrating MФs into the CNS are believed to play a prominent role in its development and/or progression (for review, see Hong and Banks [17]). Recently, we reported mild-to-moderate accumulation of $\mathrm{CD}_{163^{+}}$ perivascular MФs and microglia in autopsy brain from anti-retroviral treated-HIV-infected persons without encephalitis, although to a much lesser degree than that seen in HIV encephalitis (HIVE), a histopathological correlate of the most severe form of HAND, HIVassociated dementia (HIV-D) [18]. This observation, as well as other indications of neuroinflammation in all $\mathrm{HIV}^{+}$cases studied, suggests that chronic neuroinflammation, even in the absence of productive infection in the brain, is a common feature of HIV and likely contributes to all degrees of HAND.

Expression of CD163 has been used to phenotypically identify a subclass of M2 MФs [19-22] (for review, see Moestrup and Møller [23]), suggesting that the observed $\mathrm{CD}_{163^{+}} \mathrm{M} \Phi \mathrm{s}$ and microglia in brain are M2 activated/ polarized. The inciting factor(s) of $M \Phi$ polarization in the context of HIV infection, however, is/are unknown. A leading candidate molecule in M2 polarization of MФs in HIV infection is macrophage-colony stimulating factor (M-CSF). M-CSF has been shown in cerebrospinal fluid (CSF) of HIV-infected patients $[24,25]$ and is believed to support virus production and disease progression (for review, see Haine et al. [26]). We recently identified the MФs accumulating perivascularly and within nodular lesions as the principal source of M-CSF in simian immunodeficiency virus (SIV)-infected rhesus macaques, a relevant animal model for HIV-associated neuropathogenesis [27], with encephalitis (SIVE). In this same study, we found expression of IL-34, which shares the same receptor, cFMS, but appeared to have a greater association with cells in the parenchyma, rather than those accumulating perivascularly and within nodular lesions [27].

To further characterize these cells and explore the potential relationship of M-CSF and/or IL-34 with M2 activation, we performed immunohistochemical analyses of brain tissue from non-infected and SIVinfected rhesus macaques, with and without encephalitis (SIVE), to investigate the association between CD163 expression with M-CSF and IL-34. Here, we report that the $\mathrm{CD}_{163}{ }^{+} \mathrm{M} \Phi$ s that accumulate perivascularly and within nodular lesions and serve as the primary reservoir of productive SIV and HIV infection in the CNS $[28,29]$, also appear to be the primary source of M-CSF in SIVE. In contrast, CD163 expression in the parenchyma does not co-localize considerably with M-CSF, but does with IL-34. In addition, neurons also express M-CSF and IL-34, which is altered in SIV infection, suggesting a potential mechanism by which neurons communicate with neighboring microglia. Finally, our in vitro studies of rhesus macaque and human peripheral blood mononuclear cells (PBMC) demonstrate that cFMS signaling via either of its ligands may contribute to sustained M2 activation in brain in SIV infection and SIVE.

\section{Methods}

\section{Immunohistochemistry}

Sections from archival frontal lobe brain tissue $(4 \mu \mathrm{m})$ of eight SIVmac251 infected and two non-infected rhesus macaques were kindly provided by Dr. Jay Rappaport. Sections include both frontal white matter (FWM) and frontal grey matter (FGM). Four of the eight SIV-infected animals had SIVE, characterized by the presence of perivascular cuffs, nodular lesions, and multinucleated giant cells, which are histological hallmarks of both HIV and SIV encephalitis [30-33]. Immunohistochemistry was performed as described by us previously $[28,34,35]$. Briefly, deparaffinized and rehydrated 4- $\mu \mathrm{m}$ brain tissue sections underwent high heat non-enzymatic antigen retrieval, followed by blocking with $20 \%$ normal goat (Lampire Biological 
Laboratories, Pipersville, USA) or horse (Fisher Scientific, Waltham, USA) serum and overnight incubation with primary mouse monoclonal CD163 (1:100; Vector Laboratories, Burlingame, USA), M-CSF (1:12.5; Novus Biologicals, Littleton, USA) or rabbit polyclonal IL-34 (1:200; Abcam, New Territories, Hong Kong) antibodies. The spleen from non-infected rhesus macaques was used as a positive control. Negative controls consisted of isotype antibodies used in place of the primary and tissues incubated in buffer without primary antibody. Antigen-specific staining was detected with goat- $\alpha$-rabbit or horse- $\alpha$-mouse biotinylated antibodies (Vector Laboratories), followed by Vectastain ABC Alkaline Phosphatase and Vector Red Alkaline Phosphatase Substrate Kit (Vector Laboratories), according to the manufacturer's instructions. Tyramide signal amplification (Perkin Elmer, Waltham, USA) was used for CD163 and IL-34 detection, according to the manufacturer's instructions. Following a light counterstain with hematoxylin, sections were dehydrated in xylenes, coverslipped with Permount, and analyzed under light microscopy. Immunohistochemistry for each antigen of interest was performed in a single run for all animals/ groupings.

\section{Immunohistochemistry quantification}

Quantification of single-label CD163, M-CSF, and IL-34 expression in brain among the three test animal groupings was completed using a bioquantification software system (Bioquant Image Analysis Program). A total of $12 \times 20$, microscopic fields of $0.31 \mathrm{~mm}^{2}$ each were assessed per brain section using a microscope (Nikon, Tokyo, Japan) with a motorized $x, y$ stage and a digital camera (Q-Imaging Retiga, Surrey, Canada) that were linked to a computer with the software program. An unbiased quantification approach was used, with a random start, and then systematic sampling of 12 adjacent (nonoverlapping) sites within the brain region of interest using the motorized stage option. Analysis conditions were retained across animals/groupings for each antigen of interest by white-balancing the camera prior to data acquisition and maintaining the same light intensity of the microscope for each slide. The Videocount Area Array and color thresholding options of the Bioquant software were utilized for these measurements, as previously defined in detail [36]. Briefly, videocount (VC) area is defined as the number of pixels in a field that meet a user-defined color threshold of staining. The userdefined color threshold of immunostaining for each antigen (that is, positivity of each antigen) was defined by setting the red-green-blue values to detect the range of positive signal values for a particular immunostained antigen, while excluding color ranges of other antigens and background noise. The threshold values for each antigen were stored in the computer program and maintained for each immunohistochemical analysis across all animals and groupings. The inclusion of positive cells and exclusion of potential background noise was verified by viewing the image of positive area projected onto the computer screen. Inappropriate inclusions/exclusions were corrected manually. The percent positivity for each field and antigen was determined by dividing the number of positive pixels (those that matched the defined color threshold) by the total number of pixels within the $\mathrm{VC}$ area, which were multiplied by 100. Data are expressed as the percentage of antigen positivity per $0.31 \mathrm{~mm}^{2}$ field. The assessment was carried out in a blinded fashion.

\section{Isolation of PBMC and cell culture}

Whole blood from two non-infected, healthy rhesus macaques was acquired from Bioqual, Rockville, MD, USA, in accordance with Bioqual Institutional Animal Care and Use Committee protocol \#14-3027-56. Buffy coat from a de-identified human volunteer was acquired from Biological Specialty Corporation in Colmar, PA, USA. The Biological Specialty Corporation is an FDA-licensed facility (US license \#856) and abides by all applicable federal and state regulations concerning the collection and distribution of whole blood and blood products. PBMC were isolated by density gradient from heparinized blood or buffy coat using ACCUSPIN Tubes (Sigma, St. Louis, USA) containing Histopaque-1077 (Sigma). Viable PBMC were plated at $5 \times 10^{6}$ cells $/ \mathrm{ml}$ in Costar 24-well cell culture plates (Corning, Tewksbury, USA) and maintained in RPMI 1640 with L-glutamate (ThermoScientific, Waltham, USA) supplemented with penicillin/streptomycin (Cellgro, Manassas, USA) and $2 \%$ FBS. PBMC were maintained at $37^{\circ} \mathrm{C}$ and $5 \%$ $\mathrm{CO}_{2}$ for $24 \mathrm{~h}$ in media with and without $2.5 \mathrm{ng} / \mathrm{ml}$ recombinant human (rh)M-CSF (R\&D, Minneapolis, USA) or rhIL-34 (R\&D) and with and without $4.7 \mu \mathrm{M}$ or 470nM GW2580 (Calbiochem, Billerica, USA). Brefeldin A (eBioscience, San Diego, USA) was added to each well $6 \mathrm{~h}$ prior to harvest. PBMC were harvested and washed with FACS Wash (FW; Hanks' Balanced Salt Solution (ThermoScientific), 3\% normal horse serum (NHS) (ThermoScientific), $0.02 \%$ sodium azide (Fisher)) and prepared for flow cytometric analysis.

\section{Flow cytometric analyses}

Flow cytometric analyses were performed on cultured human and rhesus macaque PBMC, using fluorochromeconjugated antibodies, CD14-PCP-Cy5.5 (M5E2, BD, Franklin Lakes, USA), CD163-PE (Mac2-158; Trillium Diagnostics, Maine, USA), CD16-Pacific Blue (3G8, BD), and IL-10APC (JES3-19 F1, BD) as described previously [37]. The antibody-fluorochrome panel was designed according to optimized detection and required information. Isotype controls 
were utilized in the construction of the panel ensure the specificity of each antibody in the panel. Fluorescence minus one (FMO) tests and non-stained PBMC were used for gating. For each test, 30,000 events were collected on a 4-laser 13-color LSRII Analyzer (BD) and analyzed using FlowJo version 10.0.7r2 (TreeStar, Ashland). Following identification of single events and live/dead discrimination using a Live/Dead Fixable Blue Dead Cell Stain Kit (Invitrogen, Grand Island, USA), monocytes were defined within a broad gate, based on forward scatter (FSC) and side scatter (SSC) properties. Identification of monocytes was further refined by expression of CD14, a lipopolysaccharide (LPS) receptor routinely used as a lineage marker for monocytes. $\mathrm{CD}_{14}{ }^{+}$monocytes are the parent population for all monocyte populations/subsets described in this manuscript. Representative dot plots demonstrate gating strategies used in identifying the $\mathrm{CD} 14^{+}$parent population and specific monocyte subsets under the different treatment conditions (Figure 1).

\section{Statistical analyses}

The frequencies of $\mathrm{CD}_{163}{ }^{+}, \mathrm{M}_{-} \mathrm{CSF}^{+}$, and $\mathrm{IL}_{-} 34^{+}$populations in brain and the percent frequencies of $\mathrm{M}^{-\mathrm{CSF}^{+}}$ and $\mathrm{IL}-34^{+}$monocyte $\left(\mathrm{CD} 14^{+}\right)$populations from the in vitro studies were compared using ordinary and repeated measures one-way ANOVA with Tukey's multiple comparisons post-test. Pearson correlations were performed to evaluate potential relationships between monocyte subsets investigated in the in vitro studies, as well as the results from the bioquantification of antigens of interest identified by immunohistochemistry in brain tissues. Statistical analyses were performed using Prism 6 for Mac OS X (GraphPad Software, version 6.0d). $P$ values $\leq 0.05$ were considered statistically significant.

\section{Results \\ The frequency of $\mathrm{CD}_{163^{+}}$brain MФs/microglia is increased in SIVE}

As others and we have shown previously, considerable accumulation of $\mathrm{CD}_{163^{+}} \mathrm{M} \Phi \mathrm{s}$ and microglia is seen in SIVE brain [35,38-40] (Figure 2). In the brain of noninfected animals, CD163 expression is largely limited to the perivascular $M \Phi$, with little to no immunopositivity detected in the parenchymal white matter (Figure 2A, D). Infrequent areas of CD163 expression are seen in the parenchymal white matter in SIV infection (Figure 2B); however, this appears to be considerably less than that observed in SIVE (Figure 2C). Likewise, a slight accumulation of $\mathrm{CD}_{163}{ }^{+}$perivascular $\mathrm{M} \Phi \mathrm{s}$ is seen in SIVinfected animals without encephalitis (Figure 2E), as compared to non-infected animals (Figure 2D), but without the significant cuffing characteristic of SIVE (Figure 2F). In addition to CD163 expression by MФs accumulating perivascularly in SIVE brain, MФs comprising nodular lesions are also $\mathrm{CD}_{163}{ }^{+}$(Figure 2G).

Although microglial expression of CD163 is seen in the parenchymal white matter in SIV infection without encephalitis, it does appear to be greater in SIVE. To determine the extent of parenchymal CD163 expression in SIV and SIVE, we utilized a bioquantification software system to quantify parenchymal CD163 positivity in cerebral white matter of non-infected and SIV-infected rhesus macaques, with and without encephalitis, excluding perivascular cuffs and nodular lesions in SIVE. This reveals an overall marked accumulation of $\mathrm{CD}_{163}{ }^{+} \mathrm{M} \Phi$ s and microglia in SIVE, as compared to the SIV without encephalitis and non-infected groupings (Figure $2 \mathrm{H}$ ). It does not reach statistical significance, however, presumably due to the small number of animals in the study and the presence of a single outlier in each of the $\mathrm{SIV}^{+}$and SIVE groupings.

\section{M-CSF, but not IL-34, expression is associated with CD163 ${ }^{+}$ MФs that accumulate perivascularly and within nodular lesions in SIVE}

Recently, we reported that both known ligands for cFMS, M-CSF and IL-34, are expressed in white matter of non-infected and SIV-infected rhesus macaques [27]. These studies showed that while IL-34 expression remained unchanged in cerebral white matter, irrespective of SIV infection or the development of SIVE, M-CSF expression appeared to be decreased by parenchymal cells in SIV and SIVE, but with significant expression by cells accumulating perivascularly and within nodular lesions in SIVE brain [27]. IL-34 also appeared to be expressed by some cells in these areas of pathology but to a markedly lesser degree than M-CSF [27]. To further characterize the IL-34 and M-CSF expressing cells in SIVE, we explored a potential relationship between MCSF and/or IL-34 expression with $\mathrm{CD}_{163^{+}} \mathrm{M \Phi s/micro-}$ glia through double-label immunohistochemistry studies. These studies reveal little co-localization of CD163 (Figure 3A) and M-CSF (Figure 3B) in the parenchymal white matter (Figure 3C); however, M-CSF does appear to be produced by other $\mathrm{CD}_{163^{-}}$cells (Figure 3C). In contrast, significant co-localization of CD163 with M-CSF is seen in cells that accumulate perivascularly and within nodular lesions (Figure 3F,I).

In contrast to M-CSF, some $\mathrm{CD}_{163^{+}}$parenchymal microglia appear to express IL-34 in SIVE (Figure 4A,B, C). Additionally, numerous glia, not positive for CD163, also appear to express IL-34 (Figure 4C). While IL-34 expression is seen in MФs/microglia in the vicinity of perivascular cuffs (Figure 4E), it is not seen to a great extent by cells that comprise the cuffs, themselves (Figure 4F). As compared to cuffs, IL-34 is more highly expressed within nodular lesions (Figure $4 \mathrm{H}$ ); however, little overlap with CD163 is seen (Figure 4I). 


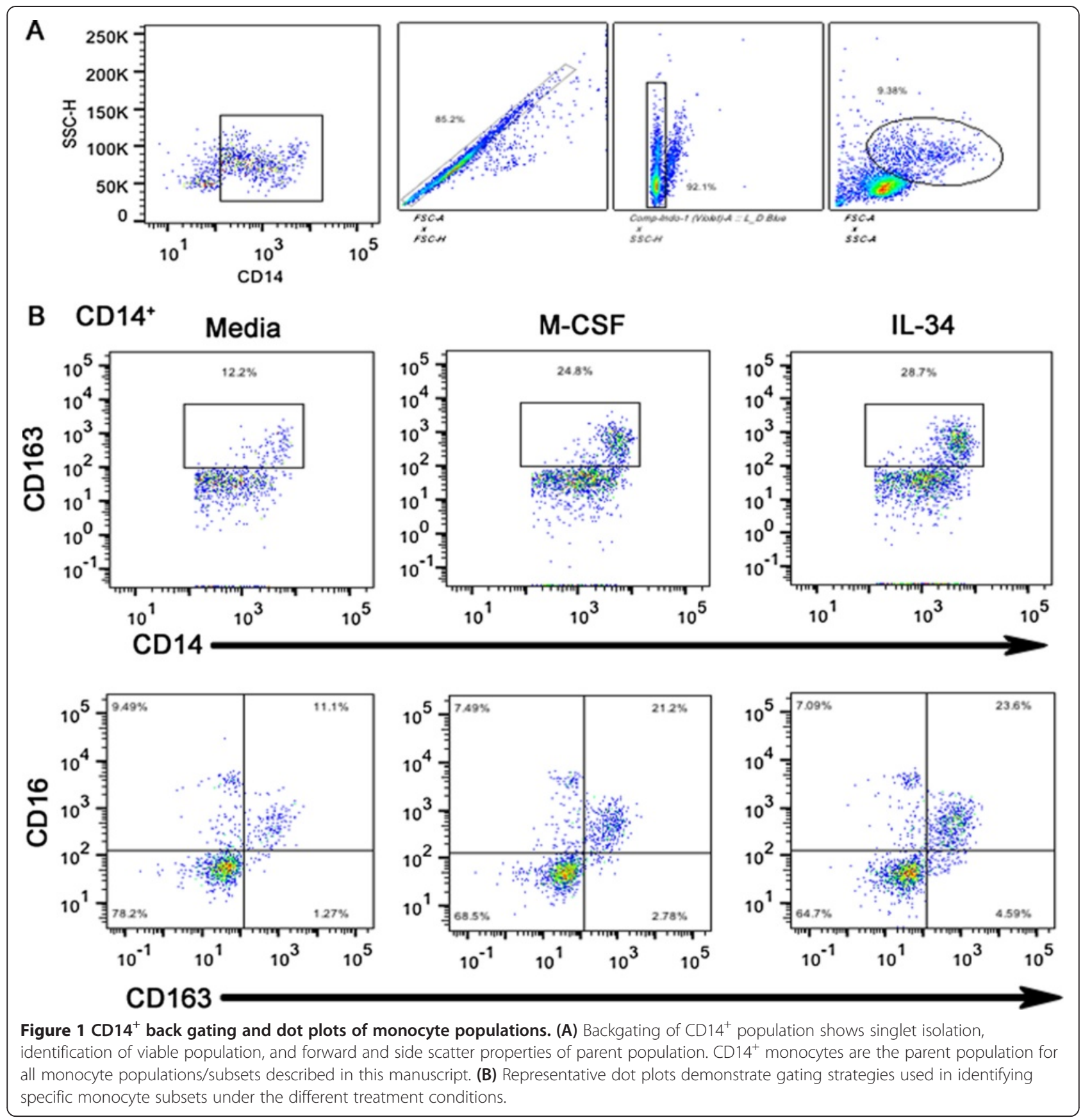

M-CSF and IL-34 are normally expressed by neurons in brain, which is altered with SIV infection

In addition to M-CSF and IL-34 expression by cells in cerebral white matter, neurons also express both cytokines in brain of non-infected (Figure 5A,D), as well as SIVinfected rhesus macaques without and with encephalitis (Figure 5B,C,E,F). Bioquantification of neuronal M-CSF expression revealed that it is significantly decreased in SIV infection, with an even greater reduction seen in those with encephalitis (Figure 5G). In contrast, bioquantification of IL-34 expression by neurons shows an overall increase in expression by animals with SIVE (Figure $5 \mathrm{H}$ ), as compared to those without encephalitis and noninfected animals; however, this does not reach statistical significance in this small study.

\section{cFMS signaling alters $\mathrm{CD} 16^{+} \mathrm{CD} 163^{+}$monocyte frequency} in vitro

Previous studies have demonstrated that M-CSF promotes expression of CD16 by monocytes in vitro $[41,42]$, which as we have shown co-localizes markedly with CD163 by perivascular MФs and parenchymal microglia 


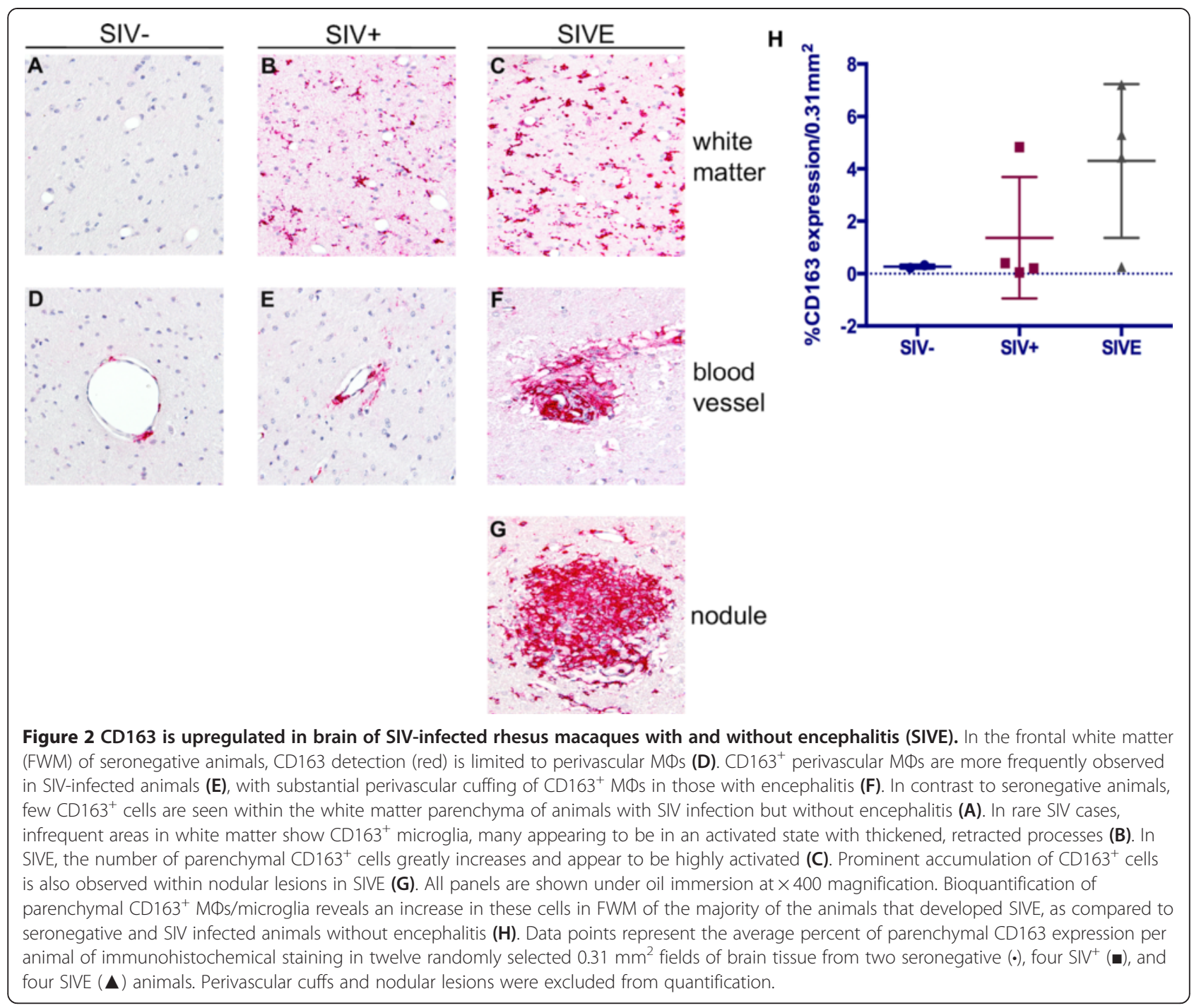

in the brain of patients with HIVE [35]. To begin to understand the mechanisms driving $\mathrm{CD} 16^{+} \mathrm{CD} 163^{+}$ expression by MФs and microglia in HIVE and SIVE, we examined the effect of M-CSF and IL-34, which also exerts its biological effects through the same M-CSF receptor, cFMS receptor tyrosine kinase, on rhesus macaque and human monocyte subset frequencies in vitro. PBMC, isolated from whole blood of two noninfected, healthy rhesus macaques and one human buffy coat, were cultured in complete RPMI containing $2 \%$ FBS and supplemented with $2.5 \mathrm{ng} / \mathrm{ml} \mathrm{M-CSF}$ or IL-34 with and without GW2580, a tyrosine kinase inhibitor (TKI) reported to have high specificity for their shared receptor, cFMS. After $24 \mathrm{~h}$, harvested cells were analyzed by flow cytometry for alterations in CD16 and CD163 expressing monocyte subsets (Figure 1). These studies demonstrated no effect of M-CSF exposure on CD163 ${ }^{+}$ or $\mathrm{CD}_{16}{ }^{+} \mathrm{CD} 163^{+}$rhesus macaque monocyte $\left(\mathrm{CD} 14^{+}\right)$ frequency, as compared to those without M-CSF treatment (Figure 6A). Interestingly, PBMC cultured in the presence of M-CSF and the cFMS inhibitor, GW2580, did show a decrease in the frequency of both monocyte subsets that reached statistical significance for the $\mathrm{CD}_{163}{ }^{+}$population (Figure 6A). Although it is unclear what may have influenced the monocyte subset frequencies in non-treated cultures, the finding that inhibiting cFMS signaling reduces these frequencies supports a role for cFMS in their expansion. No influence on IL-10 expression was observed with M-CSF exposure or cFMS inhibition (Figure 6A).

In contrast to M-CSF, IL-34 treatment of rhesus macaque PBMC did increase both the $\mathrm{CD}_{163^{+}}$and $\mathrm{CD} 16^{+}$ $\mathrm{CD}_{163^{+}}$monocyte subset frequencies, but these increases did not reach statistical significance (Figure 6B). Like M$\mathrm{CSF}$, the IL- $10^{+}$monocyte frequency remained unchanged with IL-34 exposure (Figure 6B).

In vitro studies utilizing human $\mathrm{PBMC}$ showed that both cytokines increased the frequency of $\mathrm{CD}_{163}{ }^{+}$ 

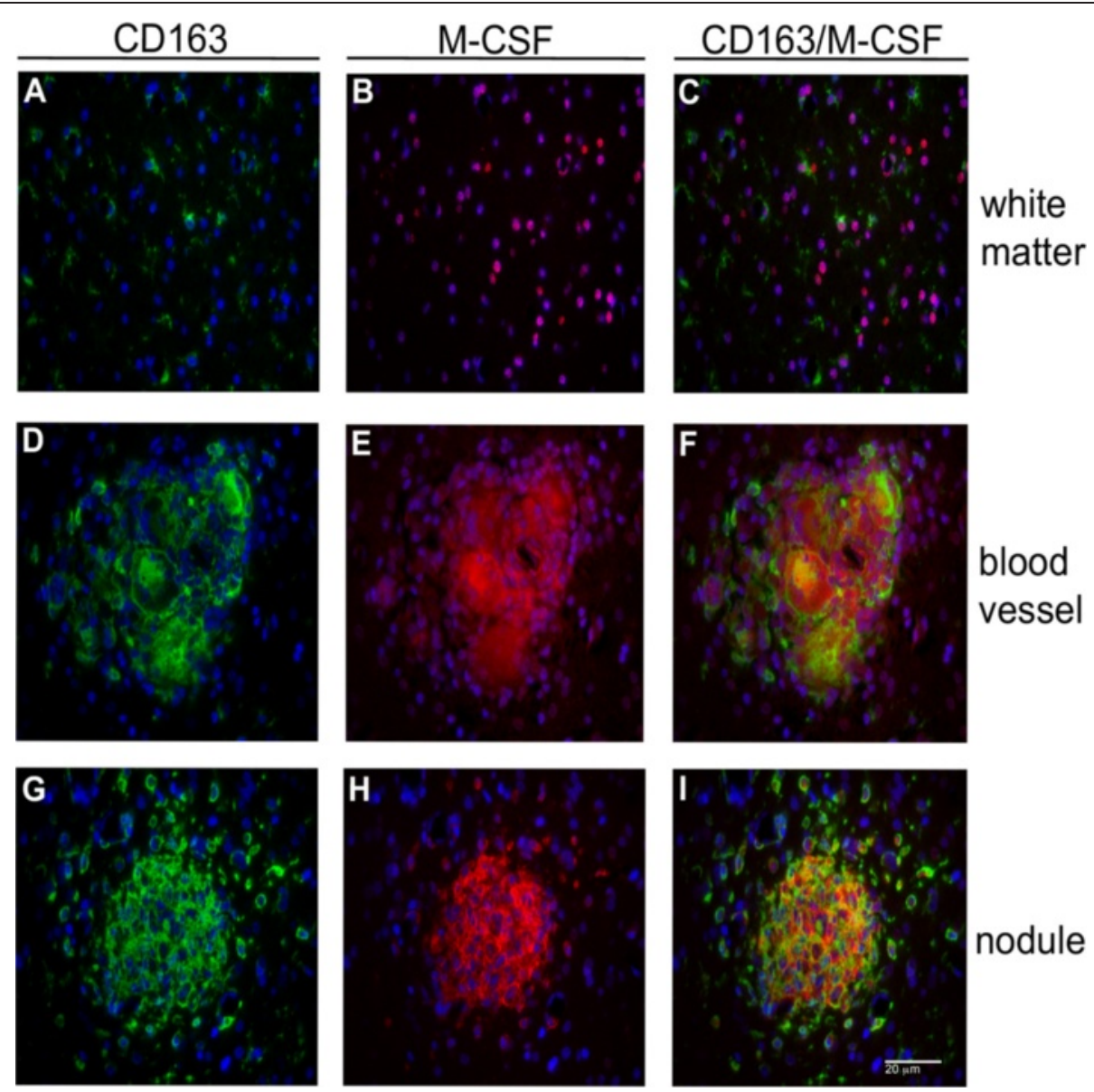

Figure 3 Accumulating perivascular and nodular CD163 ${ }^{+} \mathrm{M \Phi s} /$ microglia are a major source of M-CSF in SIVE. Parenchymal CD $163^{+}$ microglia (A) do not appear to express M-CSF in white matter (C); however, M-CSF is produced by other glia (B). Significant co-localization of CD163 (D, G) and M-CSF (E, H) is seen within perivascular cuffs and nodular lesions (F, I) and appears to be the principal source of M-CSF in SIVE brain.

and $\mathrm{CD} 16^{+} \mathrm{CD} 163^{+}$monocytes $\left(\mathrm{CD} 14^{+}\right)$, as compared to cells cultured without cytokine supplementation (Figure 7). Due to a greater number of PBMC recovered from the human buffy coat than the rhesus macaques, we investigated two different concentrations of GW2580 for its ability to counter these phenotypic alterations exerted on monocytes by M-CSF and IL34. Both concentrations were able to effectively reduce the frequency of $\mathrm{CD} 163^{+}$and $\mathrm{CD} 16^{+} \mathrm{CD} 163^{+}$ monocytes cultured in the presence of either cytokine (Figure 7A,B), strongly supporting the notion that cFMS signaling promotes CD163 and CD16 expression. Although CD16 and CD163 expression by M-CSF treated monocytes is markedly changed with treatment or cFMS inhibition, statistical significance is not reached due to variability seen among cultures, which were performed in triplicate. In contrast, statistical significance is seen with IL-34 treatment and likely reflects the higher affinity IL-34 has for cFMS
[43]. Although, like the rhesus macaque PBMC studies, no difference in $\mathrm{IL}-10^{+}$monocyte subset frequency was seen with M-CSF treatment, a small, but statistically significant increase in this population was observed with IL-34 treatment (Figure 7B).

\section{The frequency of IL-34 expanded CD $163^{+}$monocytes} correlates with IL- $10^{+}$monocytes in vitro

Because a small but statistically significant increase in the $\mathrm{IL}-10^{+}$monocyte subset frequency was observed with IL-34 treatment, additional statistical analyses were employed to investigate potential relationships between $\mathrm{IL}-10^{+}$monocyte subset frequencies and the frequencies of other monocyte subsets of interest. Pearson's correlations revealed a fairly strong correlation between the frequencies of $\mathrm{CD}_{163}{ }^{+}$and IL- $10^{+}$monocytes (Figure 8A). This relationship remains significant when further fractionated into $\mathrm{CD}_{163^{+}}$monocytes that also express CD16 (Figure 8C), but not when compared to CD16 

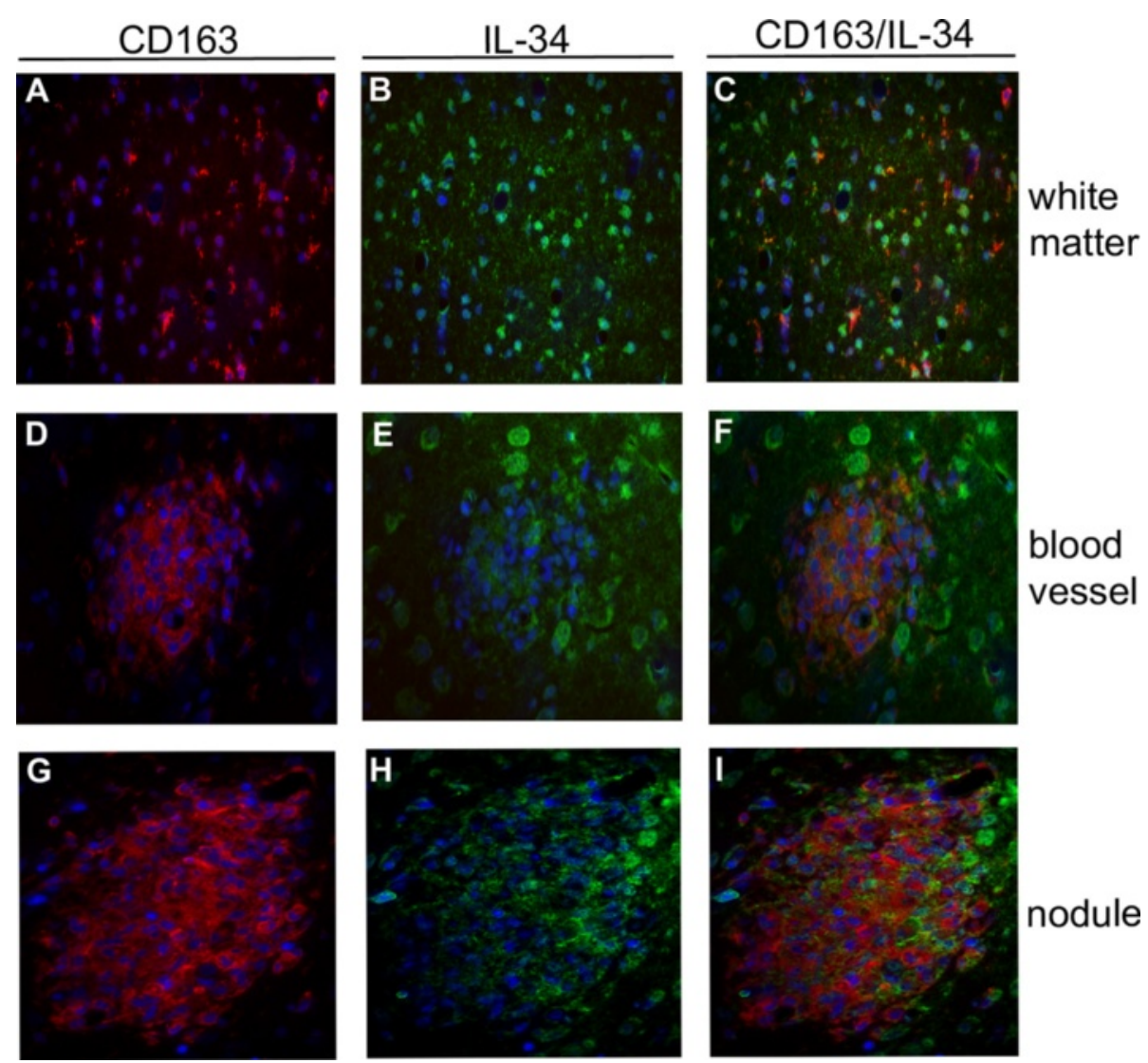

Figure 4 Parenchymal CD163 ${ }^{+}$microglia, but not perivascular or nodular CD163 ${ }^{+}$MФs, express IL-34 in FWM of rhesus macaques with SIVE. In white matter, CD163 ${ }^{+}$microglia (A), as well as other glia (B), express IL-34 (C). IL-34 expression appears to be limited to cells within the vicinity of perivascular cuffs (E), as CD163 $3^{+}$MDs that accumulate perivascularly (D) do not appear to express appreciable levels of IL-34 (F). In contrast to perivascular cuffs, IL-34 is more highly expressed within nodular lesions (H). These lesions are comprised largely of CD163 $3^{+} \mathrm{M \Phi s}(\mathbf{G})$, however, little overlap with IL-34 is observed (I).

monocyte frequencies not subfractionated by CD163 expression (Figure 8B).

\section{Discussion}

In earlier work, we found that the $\mathrm{CD}_{163^{+}} \mathrm{M \Phi s}$ that accumulate perivascularly and within nodular lesions also appear to be the principal reservoir of productive HIV infection in the brain [28]. More recently, we reported that the principal source of M-CSF in SIVE are the MФs that accumulate perivascularly and within nodular lesions [27]. Here, we demonstrate that these MФs are also $\mathrm{CD}_{163^{+}}$. We previously suggested that the MФs/ microglia that accumulate perivascularly and within nodular lesions in HIV have recently entered the CNS from the peripheral blood [28,44]. As such, peripheral blood monocytes/MФs may be the major source of MCSF in the brain in HIV infection, which is elevated in CSF of individuals with HIV infection and impaired cognition $[24,25]$.
The role of M-CSF in HIV infection and associated CNS disease is unclear. Here, we demonstrate that M-CSF and IL-34, which is also expressed in brain and shares the same receptor, cFMS, promotes expansion of the $\mathrm{CD} 16^{+} \mathrm{CD} 163^{+}$monocyte subset. Inhibiting cFMS signaling with a small molecule TKI with high specificity for cFMS attenuates this expansion. These $\mathrm{CD} 16^{+} \mathrm{CD} 163^{+}$ monocytes are phenotypically similar to monocytes we find expanded in circulation of viremic HIV-infected persons [34]. Moreover, they are similar to MФs/microglia that accumulate in the brain of patients with HIV infection with and without encephalitis [18,28,34,35]. Although co-localization of CD16 and CD163 is observed on both parenchymal microglia and MФs comprising perivascular cuffs and nodular lesions, it is the perivascular and nodular MФs that appear to be the primary reservoir of productive virus in the brain $[28,35]$. Interestingly, MФs accumulating in these regions are also the principal source of M-CSF in SIVE brain. In vitro studies have demonstrated M-CSF 


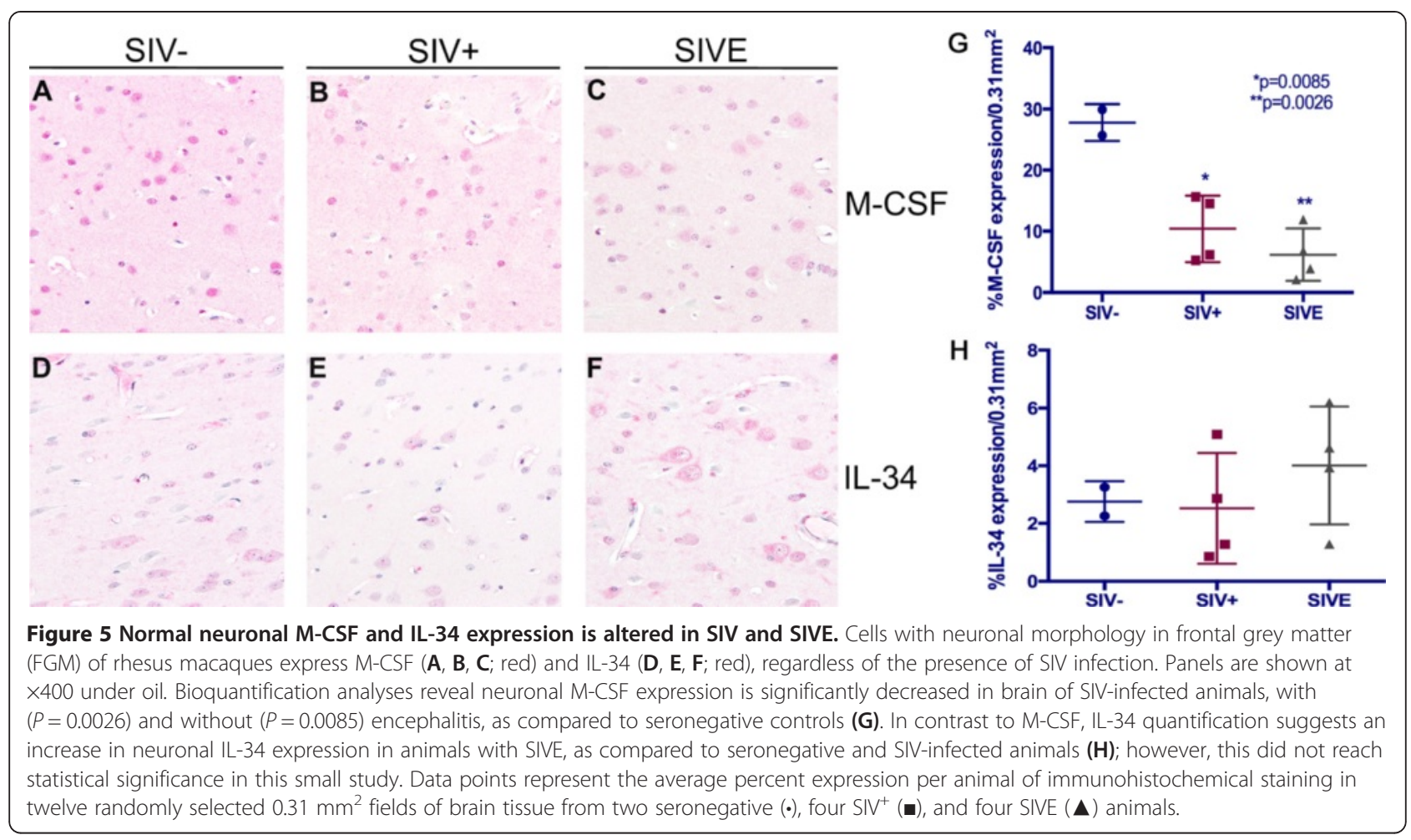

enhances the susceptibility of MФs to HIV infection and promotes virus replication [45-47]. In turn, HIV infection of MФs promotes production of M-CSF [45], constituting a positive feedback loop that supports HIV production/infection. In addition to its natural role as a key factor in MФ survival, M-CSF may serve as a key factor in the development of MФs as a long-lived cellular reservoir of HIV/SIV infection. Together, these findings support a pathological role for M-CSF in both the development and establishment of tissue reservoirs of HIV-infected MФs.

M-CSF may also contribute to the development and maintenance of tissue reservoirs, as well as neuropathogenesis, by enhancing migration of monocytes/MФs, some of which may be infected, into the brain. In support of this hypothesis, we previously reported that the MФs comprising perivascular cuffs and nodular lesions also express markers that suggest recent entry from the peripheral blood into the CNS compartment [28,34]. M-CSF has been shown to stimulate monocyte migration in vitro and in vivo, which is mediated through the association of PI3K with phosphorylated Y721 of the activated receptor, cFMS $[48,49]$. Enhanced CD163 expression may also contribute to the invasiveness of these cells, as CD163 has been shown to augment monocyte adherence to LPS or cytokinestimulated endothelial cells [50].

M-CSF expression is also seen in $\mathrm{CD}_{163^{-}}$cells in the parenchymal white matter, although this appears to be less than that expressed by cells within perivascular cuffs and nodular lesions. These cells have not yet been identified, but may be identified as microglia that do not express CD163 or express it below the level of detection in this study. Alternatively, these may be astrocytes, as murine astrocytes have been demonstrated to express M-CSF in vitro when stimulated with IL-1 or TNF $\alpha$ [51], cytokines elevated in CSF and brain in HIV infection and believed to contribute to HIV-associated neurological impairment [52-54].

In contrast to M-CSF, IL-34 glial expression appears to be largely limited to parenchymal microglia, rather than perivascular and nodular MФs in SIVE. Additionally, IL-34 expression is largely unchanged from that observed in brain of non-infected animals and those with SIV infection but without encephalitis [27], suggesting a spatial relationship between the two cytokines in brain and, presumably, different biological roles. In support of this notion, we find that both $\mathrm{M}$ CSF and IL-34 are normally expressed by neurons, however, while neuronal M-CSF expression is decreased in SIVE, IL-34 may be increased.

Although M-CSF and IL-34 appear to have some shared roles, differences have been reported in signaling kinetics and function [43] and may exert different biological effects in response to foreign pathogens in the brain and/or maintaining brain homeostasis. IL-34 is highly expressed in brain and is a key regulator in neuronal progenitor and microglial maturation in the 
A
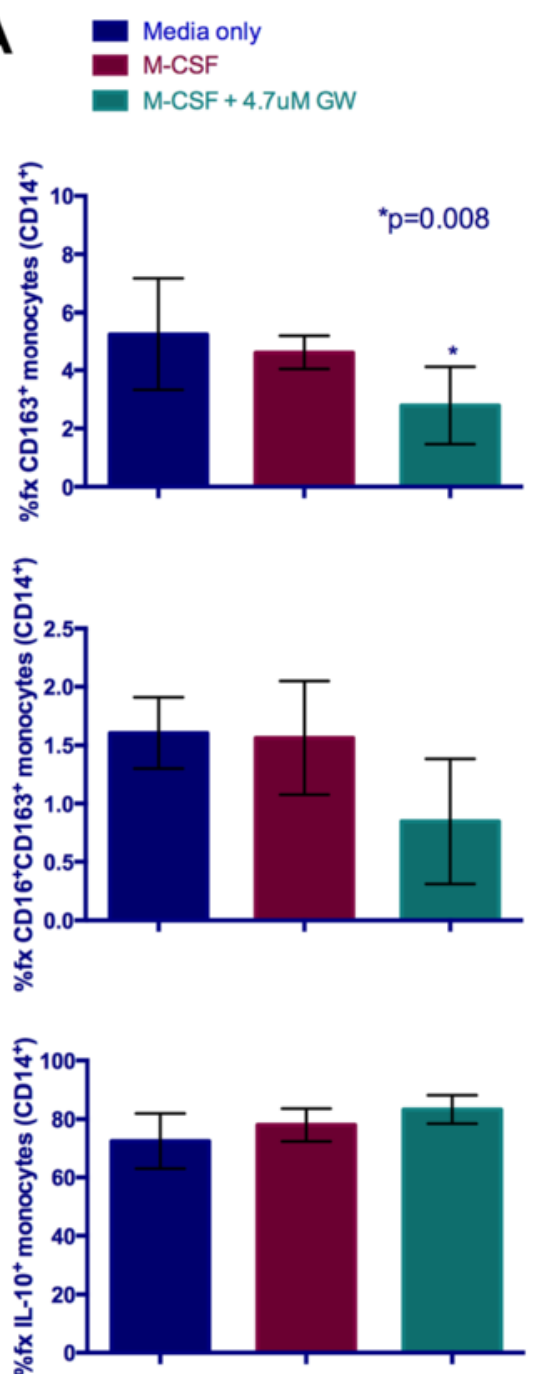

B
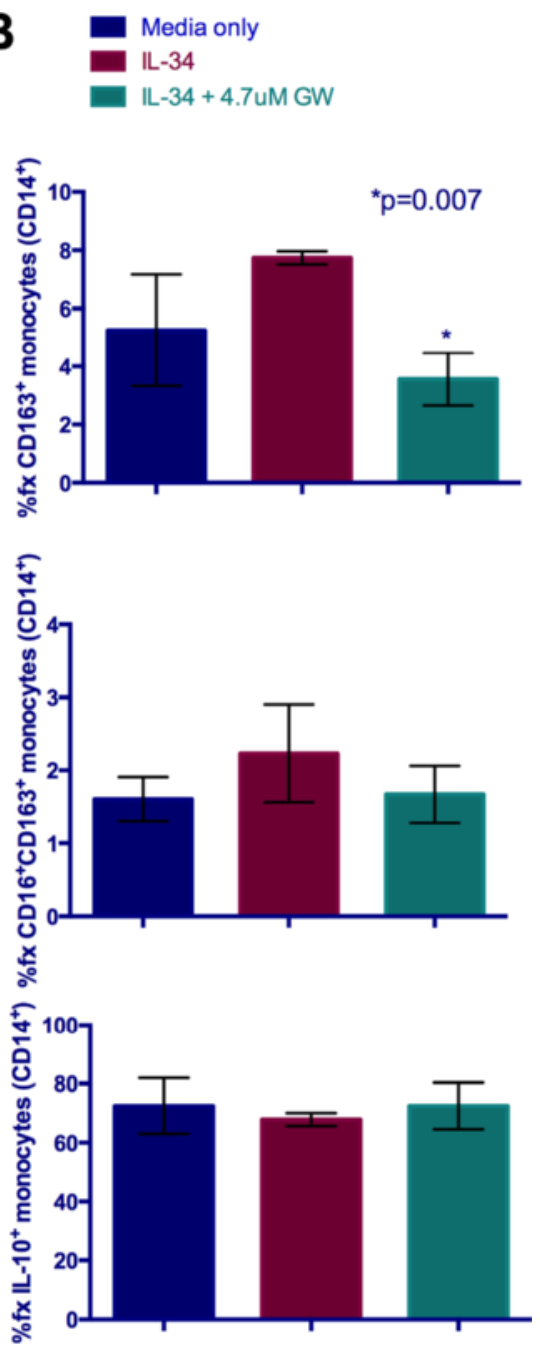

Figure 6 cFMS inhibition alters the frequency of $\mathrm{CD} 16^{+} \mathrm{CD} 163^{+}$rhesus macaque monocytes in vitro. An increase in the frequency of $\mathrm{CD}_{163}{ }^{+}$and $\mathrm{CD} 16^{+} \mathrm{CD} 163^{+}$was observed with IL-34 (B) but not M-CSF treatment (A), as compared to PBMC cultured in the presence of media only. Interestingly, the frequencies of these monocyte subsets were reduced by the addition of the tyrosine kinase inhibitor (TKI), GW2580, which may reflect inhibition of endogenous M-CSF and/or IL-34 activity in the culture. The frequency of IL-10 ${ }^{+}$monocytes was high, regardless of treatment.

developing brain [55,56] and may contribute to the survival of these cells. Systemic administration of MCSF or IL-34 in a mouse model of kainic acid-induced neurotoxicity showed a reduction in neuronal loss that appears to be a direct result of neuronal cFMS signaling [57]. In addition, activation of astrocytes and microglia also appears to be attenuated in response to M-CSF or IL-34 administration in this model [57]. This may be the result of reduced neurotoxicity, itself, affecting gliosis and/or may be a direct affect of these cytokines on astrocytes and/or microglia. In support of this notion, IL-34 treatment of microglia in vitro promotes expression of the anti-inflammatory factor, tumor growth factor- $\beta$ (TGF- $\beta$ ) [58]. It is feasible that both mechanisms contribute to neuroprotection. As such, upregulation of IL-34 by injured or stressed neurons in SIVE may be a mechanism by which neurons promote self-protection through autocrine IL-34 signaling, as well as by communicating to neighboring microglia to reduce inflammatory factors that would promote activation of surrounding glia and advance damage to neurons. Interestingly, our in vitro studies of human PBMC showed a small but statistically significant increase in IL-10 expression by monocytes. Although additional studies are needed to assess the potential biological relevance of this finding, the frequency of $\mathrm{CD} 163^{+}$monocytes correlates strongly with the frequency of monocytes positive for IL-10. If these cells are also a rich source of IL-10 in the brain, their continued presence throughout the disease process 
A
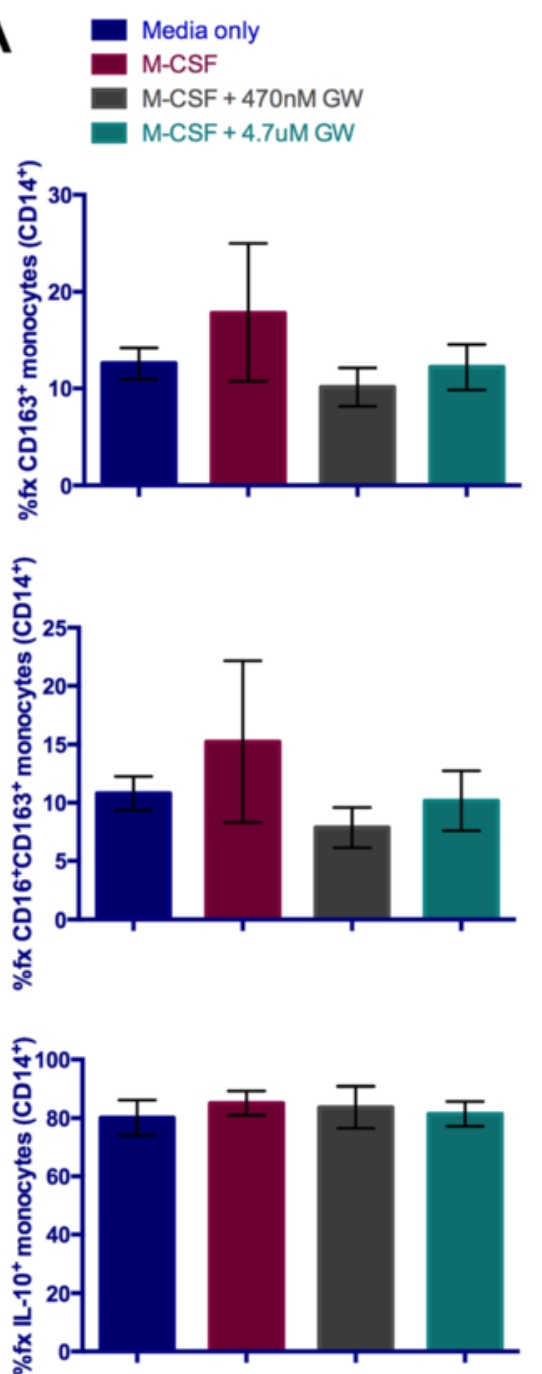

B

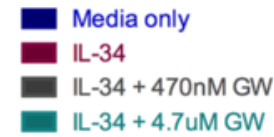

范
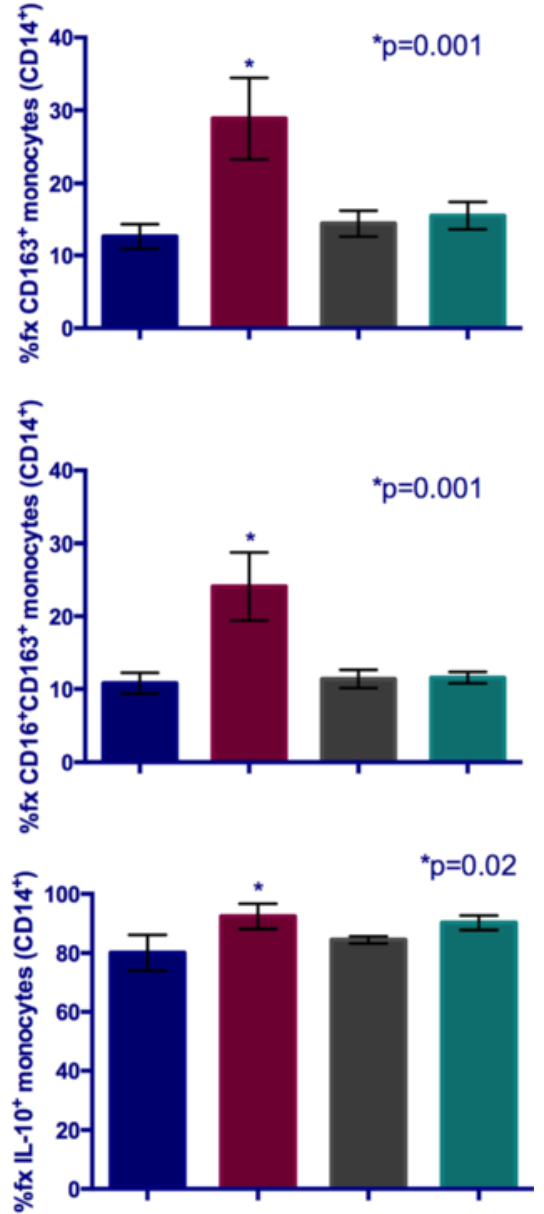

Figure $7 \mathrm{M}$-CSF and IL-34 increase the frequency of $\mathrm{CD} 16^{+} \mathrm{CD} 163^{+}$human monocytes in vitro, which is reversed by inhibition of cFMS signaling. An increase in the frequency of $\mathrm{CD} 163^{+}$and $\mathrm{CD}_{16}{ }^{+} \mathrm{CD} 163^{+}$monocytes is observed with both M-CSF (A) and IL-34 (B) but only reaches statistical significance with IL-34 treatment (B). This may reflect the reportedly high affinity IL-34 has for cFMS, suggested by decreased standard deviation seen among replicates treated with IL-34, as compared to those treated with M-CSF. The increased frequencies of these monocyte subsets are abrogated by the addition of GW2580, which restores the frequencies to percentages at or near those seen in PBMC cultured in media only. The frequency of $\mathrm{IL}-10^{+}$monocytes is high, regardless of treatment; however, a small but statistically significant increase is seen with IL-34.

may suggest a mechanism for neuropathogenesis that involves an immunosuppressive environment in the CNS that is tolerant of HIV/SIV and opportunistic pathogens, while contributing to neuropathogenesis through chronic inflammatory activation. The significant variability of neuronal IL-34 expression in SIVinfected animals without encephalitis may reflect other pro- or anti-inflammatory factors not investigated in this study.

\section{Conclusions}

Tissue MФs are increasingly recognized as an important reservoir of viral persistence in HIV infection. In the brain, infected $\mathrm{M} \Phi \mathrm{s}$ and microglia pose additional concerns due to the presence of virus and viral proteins, as well as chronic inflammation in the CNS, all of which contribute to the development and progression of HIVassociated neurocognitive impairment. Here, we demonstrate substantial M-CSF expression by $\mathrm{CD}_{163^{+}} \mathrm{M \Phi s}$ that accumulate perivascularly and within nodular lesions in SIVE, suggesting a role for M-CSF in the development and maintenance of long-lived viral MФ/ microglial reservoirs in the brain, as well as supporting M2 activation of perivascular MФs and microglia. In contrast to M-CSF expression in brain, glial IL-34 expression appears to be unchanged between healthy and 


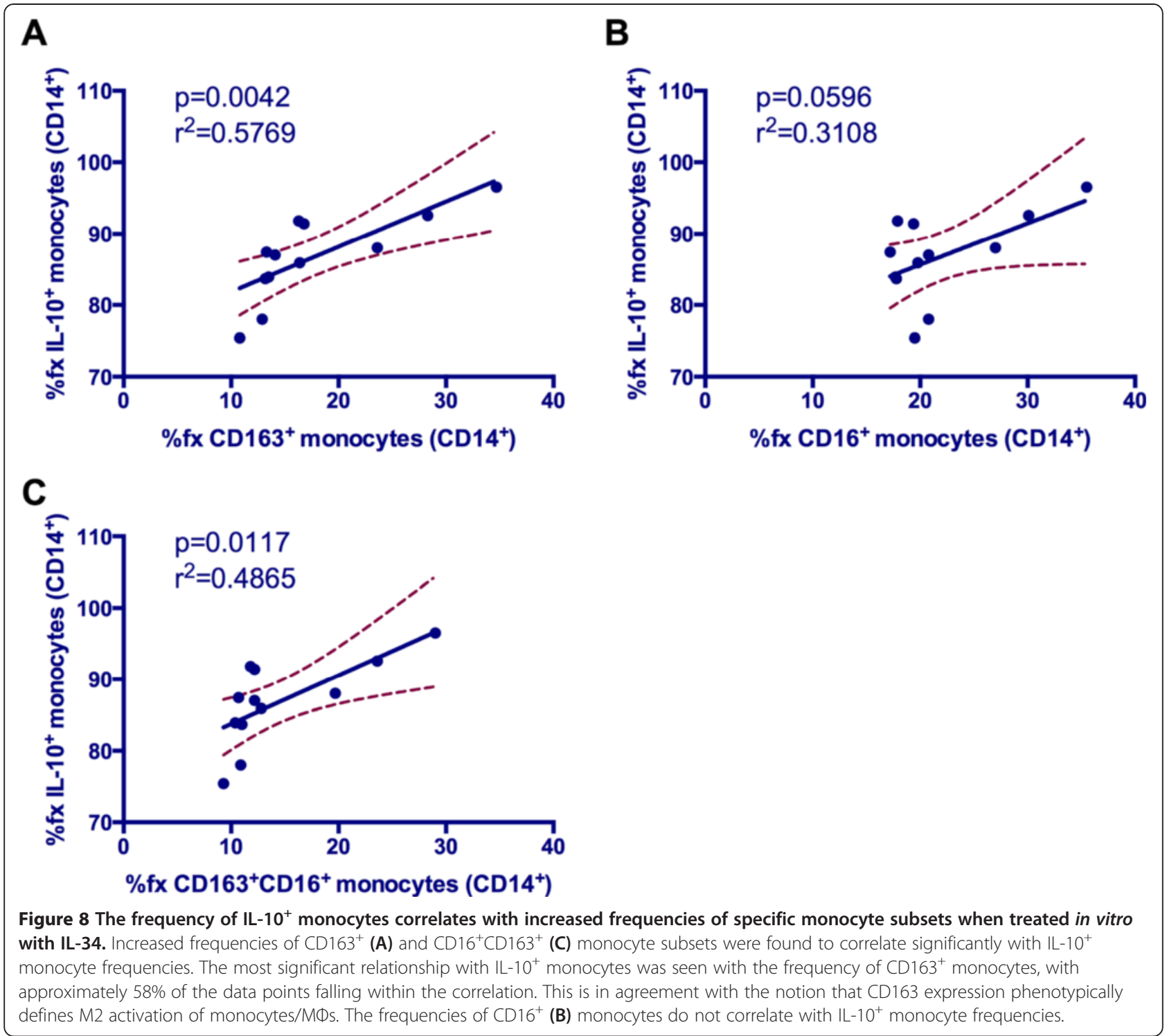

infected animals; however, neuronal IL-34 expression is actually increased in those with SIVE. As such, both cytokines may contribute to this $\mathrm{M} \Phi /$ microglial phenotype, which is consistent with $\mathrm{M} 2 \mathrm{M} \Phi$ activation.

The role of neuronal IL-34 is not clear; however, it appears to be an important factor in the developing brain [59], possibly through supporting neuronal survival. In recent work, Luo et al. demonstrated that systemic administration of either cFMS ligand is neuroprotective in a transgenic mouse model of Alzheimer's disease [57]. As neurons, astrocytes, oligodendrocytes, and microglia may all express the receptor, cFMS [57,60,61], it is unclear if this is a direct and/or indirect effect of M-CSF and/or IL-34 on neurons. Here, we find that while neuronal IL-34 is significantly increased in SIVE as compared to non-infected animals and those with SIV but without encephalitis, neuronal M-CSF expression progressively decreases in SIV and SIVE. Together, these findings of IL-34 and M-CSF expression in the brain support the idea of at least some distinct functions between the two cytokines, as well as a spatial relationship that is complementary, rather than competitive (Figure 9).

While additional studies are needed to elucidate the potentially divergent roles of M-CSF and IL-34 in HIV-associated neurodegenerative disease, these studies suggest that cFMS signaling through ligation of M-CSF plays an important role in its pathogenesis. IL-34 may also contribute to M2 activation/polarization in the brain but may also promote neuronal survival. Advancing our current understanding of the role of these partially redundant cytokines in brain health and disease will aid in the development of targeted therapeutic strategies aimed at eliminating $M \Phi$ reservoirs of HIV infection in the brain and other tissues. 


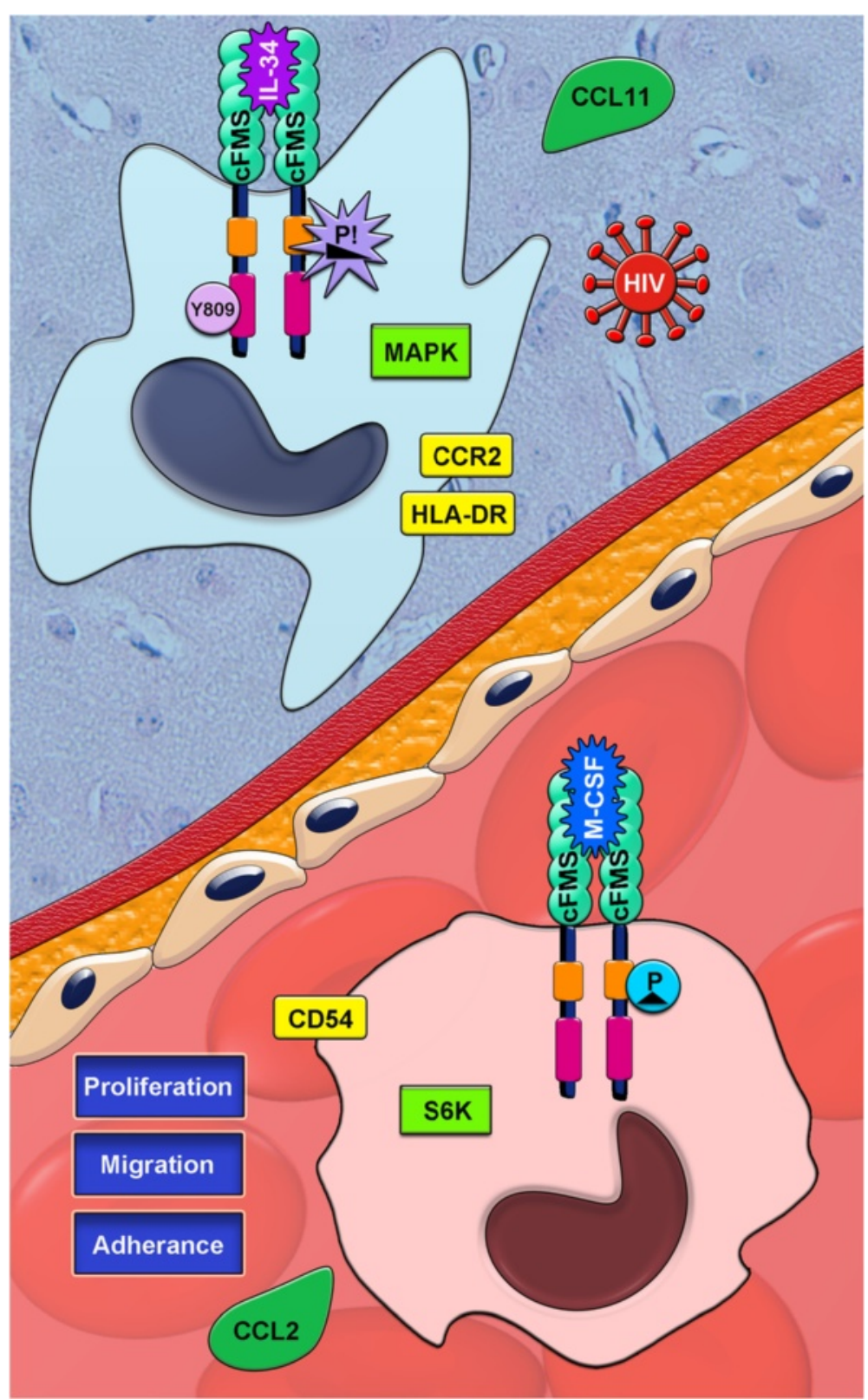

Figure 9 M-CSF and IL-34 reportedly exert different biological effects on monocyte/MФs. The limited studies comparing M-CSF and IL-34 in parallel report differences in signaling, function, and location of expression. IL-34 appears to be the dominant cFMS ligand in tissues (left, blue MФ) [56,59], where expression of M-CSF is associated more strongly with the peripheral blood and bone marrow (right, red monocyte) [62]. Upon ligation of cFMS, both cytokines phosphorylate the same intracellular tyrosine residues [43,59]; however, IL-34-mediated phosphorylation (wedge) may occur more rapidly than that mediated by M-CSF (isosceles triangle) [43]. Further, IL-34 signaling appears to decay more quickly [43] but stimulates more receptors, as compared to M-CSF [43], with the exception of Y809, which may be favored by IL-34 [43]. Following activation of second messengers, IL-34-induced signal transduction has been reported to more strongly activate the mitogen-activated protein kinases but has a weaker effect on the ribosomal S6 kinases than M-CSF [43]. Both ligands participate in chemokine-mediated chemotaxis of monocytes/MDs through upregulation of different mediators. IL-34 upregulates C-C chemokine receptor type 2 (CCR2) by primary human monocytes [63], and M-CSF promotes expression of its ligand, chemokine (C-C motif) ligand 2 (CCL2) [43]. Additionally, IL-34, but not M-CSF, promotes production of CCL11 [43], while the adhesion molecule, CD54, is upregulated by primary human monocytes more strongly by M-CSF [63]. Functionally, M-CSF, more than IL-34, promotes migration and supports proliferation in murine myeloid cell lines [43]. IL-34, however, promotes greater expression of HLA-DR [43] and may play a greater role in promoting cell-mediated immunity. In the context of productive HIV infection, both IL-34 and M-CSF promote virus production but are greater in the presence of IL-34 [43]. Together, these limited findings suggest that both CFMS ligands promote distinct populations of myeloid cells that potentially have shared, as well as specialized functions specific to M-CSF or IL-34 stimulation. 


\section{Abbreviations}

CNS: Central nervous system; CSF: Cerebrospinal fluid; FGM: Frontal grey matter; FWM: Frontal white matter; HAND: HIV-associated neurocognitive disorders; HIV: Human immunodeficiency virus; HIV-D: HIV-associated dementia; HIVE: HIV encephalitis; IL: Interleukin; M1: Classically activated MФs; M2: Alternative/type 2 activated MФs; M-CSF: Macrophage-colony stimulating factor; MФ: Macrophage; PBMC: Peripheral blood mononuclear cells; ROS: Reactive oxygen species; SIV: Simian immunodeficiency virus; SIVE: SIV encephalitis; $T_{H}$ : T helper; TKl: Tyrosine kinase inhibitor.

\section{Competing interests}

The authors declare that they have no competing interests.

\section{Authors' contributions}

LG carried out all studies, participated in study design, analyzed and prepared $\mathrm{IHC}$ images, performed flow cytometric analyses, and participated in drafting the manuscript. $G L$ and $A B$ participated in all aspects of the in vitro studies utilizing PBMC acquired from rhesus macaques, including study design, performing the experiments and data collection, and assisted with data analyses. TF conceived of the study, carried out its design and coordination, performed data and statistical analyses, and participated in drafting the manuscript. All authors have read and approved the final manuscript.

\section{Acknowledgements}

The studies presented here were supported by grants R01 NS063605 and P01 MH105303 (TF). LG was supported by T32 MH079785 (Jay Rappaport, PI). The authors would like to thank Dr. Mary Barbe and the Basic Science Core I of the Comprehensive NeuroAIDS Center (CNAC; P30 MH0921777) for assistance with the immunohistochemical quantification and Dr. Jay Rappaport for providing whole blood from seronegative rhesus macaques (R01 MH090910).

\section{Grant}

R01NS063605, P01MH105303, T32MH079785.

\section{Received: 22 October 2014 Accepted: 26 February 2015 Published online: 25 March 2015}

\section{References}

1. Amor S, Peferoen LA, Vogel DY, Breur M, van der Valk P, Baker D, et al. Inflammation in neurodegenerative diseases-an update. Immunology. 2014;142:151-66.

2. Liu YC, Zou XB, Chai YF, Yao YM. Macrophage polarization in inflammatory diseases. Int J Biol Sci. 2014;10:520-9.

3. Wang $\mathrm{N}$, Liang $\mathrm{H}$, Zen $\mathrm{K}$. Molecular mechanisms that influence the macrophage m1-m2 polarization balance. Front Immunol. 2014;5:614.

4. Ancuta P, Autissier P, Wurcel A, Zaman T, Stone D, Gabuzda D. CD16+ monocyte-derived macrophages activate resting $T$ cells for HIV infection by producing CCR3 and CCR4 ligands. J Immunol. 2006;176:5760-71.

5. Anderson CF, Mosser DM. Cutting edge: biasing immune responses by directing antigen to macrophage Fc gamma receptors. J Immunol. 2002;168:3697-701.

6. Schebesch C, Kodelja V, Muller C, Hakij N, Bisson S, Orfanos CE, et al. Alternatively activated macrophages actively inhibit proliferation of peripheral blood lymphocytes and CD4+ T cells in vitro. Immunology. 1997;92:478-86.

7. Porcheray F, Viaud S, Rimaniol AC, Leone C, Samah B, Dereuddre-Bosquet N, et al. Macrophage activation switching: an asset for the resolution of inflammation. Clin Exp Immunol. 2005;142:481-9.

8. Gratchev A, Guillot P, Hakiy N, Politz O, Orfanos CE, Schledzewski K, et al. Alternatively activated macrophages differentially express fibronectin and its splice variants and the extracellular matrix protein betalG-H3. Scand J Immunol. 2001;53:386-92.

9. Edwards JP, Zhang X, Frauwirth KA, Mosser DM. Biochemical and functional characterization of three activated macrophage populations. J Leukoc Biol. 2006;80:1298-307.

10. Fonseca JE, Edwards JC, Blades S, Goulding NJ. Macrophage subpopulations in rheumatoid synovium: reduced CD163 expression in CD4+ T lymphocyte-rich microenvironments. Arthritis Rheum. 2002;46:1210-6.
11. Weisberg SP, McCann D, Desai M, Rosenbaum M, Leibel RL, Ferrante Jr AW Obesity is associated with macrophage accumulation in adipose tissue. J Clin Invest. 2003;112:1796-808.

12. Prasse A, Germann M, Pechkovsky DV, Markert A, Verres T, Stahl M, et al. IL-10-producing monocytes differentiate to alternatively activated macrophages and are increased in atopic patients. J Allergy Clin Immunol. 2007;119:464-71.

13. Brocheriou I, Maouche S, Durand H, Braunersreuther V, Le Naour G, Gratchev A, et al. Antagonistic regulation of macrophage phenotype by M-CSF and GM-CSF: implication in atherosclerosis. Atherosclerosis. 2011;214:316-24

14. Komohara Y, Ohnishi K, Kuratsu J, Takeya M. Possible involvement of the M2 anti-inflammatory macrophage phenotype in growth of human gliomas. J Pathol. 2008;216:15-24.

15. Bloch O, Crane CA, Kaur R, Safaee M, Rutkowski MJ, Parsa AT. Gliomas promote immunosuppression through induction of B7-H1 expression in tumor-associated macrophages. Clin Cancer Res. 2013;19:3165-75.

16. Zhang Y, Choksi S, Chen K, Pobezinskaya Y, Linnoila I, Liu ZG. ROS play a critical role in the differentiation of alternatively activated macrophages and the occurrence of tumor-associated macrophages. Cell Res. 2013:23:898-914

17. Hong S, Banks WA. Role of the immune system in HIV-associated neuroinflammation and neurocognitive implications. Brain Behav Immun. 2015;45C:1-12.

18. Tavazzi E, Morrison D, Sullivan P, Morgello S, Fischer T. Brain Inflammation is a Common Feature of HIV-Infected Patients Without HIV Encephalitis or Productive Brain Infection. Curr HIV Res. 2014;12:97-110.

19. Zwadlo G, Voegeli R, Osthoff KS, Sorg C. A monoclonal antibody to a novel differentiation antigen on human macrophages associated with the down-regulatory phase of the inflammatory process. Exp Cell Biol. 1987;55:295-304.

20. Sulahian TH, Hogger P, Wahner AE, Wardwell K, Goulding NJ, Sorg C, et al. Human monocytes express CD163, which is upregulated by IL-10 and identical to p155. Cytokine. 2000;12:1312-21.

21. Nguyen TT, Schwartz EJ, West RB, Warnke RA, Arber DA, Natkunam Y. Expression of CD163 (hemoglobin scavenger receptor) in normal tissues, lymphomas, carcinomas, and sarcomas is largely restricted to the monocyte/macrophage lineage. Am J Surg Pathol. 2005;29:617-24.

22. Weaver LK, Pioli PA, Wardwell K, Vogel SN, Guyre PM. Up-regulation of human monocyte CD163 upon activation of cell-surface Toll-like receptors. J Leukoc Biol. 2007;81:663-71.

23. Moestrup SK, Moller HJ. CD163: a regulated hemoglobin scavenger receptor with a role in the anti-inflammatory response. Ann Med. 2004;36:347-54.

24. Gallo P, Pagni S, Giometto B, Piccinno MG, Bozza F, Argentiero V, et al. Macrophage-colony stimulating factor (M-CSF) in the cerebrospinal fluid. J Neuroimmunol. 1990;29:105-12.

25. Gallo P, Laverda AM, De Rossi A, Pagni S, Del Mistro A, Cogo P, et al. Immunological markers in the cerebrospinal fluid of HIV-1-infected children. Acta Paediatr Scand. 1991;80:659-66.

26. Haine V, Fischer-Smith T, Rappaport J. Macrophage colony-stimulating factor in the pathogenesis of HIV infection: potential target for therapeutic intervention. J Neuroimmune Pharmacol. 2006;1:32-40.

27. Gerngross L, Fischer T. Evidence for CFMS signaling in HIV production by brain macrophages and microglia. J Neurovirol. 2014; Jul 25 [Epub ahead of print].

28. Fischer-Smith T, Croul S, Sverstiuk AE, Capini C, L'Heureux D, Regulier EG, et al. CNS invasion by CD14+/CD16+ peripheral blood-derived monocytes in HIV dementia: perivascular accumulation and reservoir of HIV infection. J Neurovirol. 2001;7:528-41.

29. Williams KC, Corey S, Westmoreland SV, Pauley D, Knight H, deBakker C, et al. Perivascular macrophages are the primary cell type productively infected by simian immunodeficiency virus in the brains of macaques: implications for the neuropathogenesis of AIDS. J Exp Med. 2001;193:905-15.

30. Navia BA, Cho ES, Petito CK, Price RW. The AIDS dementia complex: II. Neuropathology. Ann Neurol. 1986;19:525-35.

31. Nielsen SL, Petito CK, Urmacher CD, Posner JB. Subacute encephalitis in acquired immune deficiency syndrome: a postmortem study. Am J Clin Pathol. 1984;82:678-82.

32. Baskin GB, Murphey-Corb M, Watson EA, Martin LN. Necropsy findings in rhesus monkeys experimentally infected with cultured simian immunodeficiency virus (SIV)/delta. Vet Pathol. 1988;25:456-67. 
33. Lackner AA, Smith MO, Munn RJ, Martfeld DJ, Gardner MB, Marx PA, et al. Localization of simian immunodeficiency virus in the central nervous system of rhesus monkeys. Am J Pathol. 1991;139:609-21.

34. Fischer-Smith T, Croul S, Adeniyi A, Rybicka K, Morgello S, Khalili K, et al. Macrophage/microglial accumulation and proliferating cell nuclear antigen expression in the central nervous system in human immunodeficiency virus encephalopathy. Am J Pathol. 2004;164:2089-99.

35. Fischer-Smith T, Bell C, Croul S, Lewis M, Rappaport J. Monocyte/ macrophage trafficking in acquired immunodeficiency syndrome encephalitis: lessons from human and nonhuman primate studies. J Neurovirol. 2008;14:318-26.

36. Al-Shatti T, Barr AE, Safadi FF, Amin M, Barbe MF. Increase in inflammatory cytokines in median nerves in a rat model of repetitive motion injury. J Neuroimmunol. 2005;167:13-22.

37. Fischer-Smith T, Tedaldi EM, Rappaport J. CD163/CD16 coexpression by circulating monocytes/macrophages in HIV: potential biomarkers for HIV infection and AIDS progression. AIDS Res Hum Retroviruses. 2008;24:417-21.

38. Roberts ES, Masliah E, Fox HS. CD163 identifies a unique population of ramified microglia in HIV encephalitis (HIVE). J Neuropathol Exp Neurol. 2004;63:1255-64.

39. Borda JT, Alvarez X, Mohan M, Hasegawa A, Bernardino A, Jean S, et al CD163, a marker of perivascular macrophages, is up-regulated by microglia in simian immunodeficiency virus encephalitis after haptoglobinhemoglobin complex stimulation and is suggestive of breakdown of the blood-brain barrier. Am J Pathol. 2008;172:725-37.

40. Kim WK, Alvarez X, Fisher J, Bronfin B, Westmoreland S, McLaurin J, et al. CD163 identifies perivascular macrophages in normal and viral encephalitic brains and potential precursors to perivascular macrophages in blood. Am J Pathol. 2006;168:822-34.

41. Munn DH, Cheung NK. Antibody-dependent antitumor cytotoxicity by human monocytes cultured with recombinant macrophage colony-stimulating factor. Induction of efficient antibody-mediated antitumor cytotoxicity not detected by isotope release assays. J Exp Med. 1989;170:511-26.

42. Ritter M, Buechler C, Langmann T, Orso E, Klucken J, Schmitz G. The scavenger receptor CD163: regulation, promoter structure and genomic organization. Pathobiology. 1999;67:257-61.

43. Chihara T, Suzu S, Hassan R, Chutiwitoonchai N, Hiyoshi M, Motoyoshi K, et al. IL-34 and M-CSF share the receptor Fms but are not identical in biological activity and signal activation. Cell Death Differ. 2010;17:1917-27.

44. Fischer-Smith T, Rappaport J. Evolving paradigms in the pathogenesis of HIV-1-associated dementia. Expert Rev Mol Med. 2005;7:1-26.

45. Gruber MF, Weih KA, Boone EJ, Smith PD, Clouse KA. Endogenous macrophage CSF production is associated with viral replication in HIV-1infected human monocyte-derived macrophages. J Immunol. 1995;154:5528-35.

46. Kalter DC, Nakamura M, Turpin JA, Baca LM, Hoover DL, Dieffenbach C, et al. Enhanced HIV replication in macrophage colony-stimulating factor-treated monocytes. J Immunol. 1991;146:298-306.

47. Bergamini A, Perno CF, Dini L, Capozzi M, Pesce CD, Ventura $L$, et al. Macrophage colony-stimulating factor enhances the susceptibility of macrophages to infection by human immunodeficiency virus and reduces the activity of compounds that inhibit virus binding. Blood. 1994:84:3405-12

48. Wang JM, Griffin JD, Rambaldi A, Chen ZG, Mantovani A. Induction of monocyte migration by recombinant macrophage colony-stimulating factor. J Immunol. 1988;141:575-9.

49. Sampaio NG, Yu W, Cox D, Wyckoff J, Condeelis J, Stanley ER, et al. Phosphorylation of CSF-1R Y721 mediates its association with PI3K to regulate macrophage motility and enhancement of tumor cell invasion. J Cell Sci. 2011;124:2021-31.

50. Wenzel I, Roth J, Sorg C. Identification of a novel surface molecule, RM3/1, that contributes to the adhesion of glucocorticoid-induced human monocytes to endothelial cells. Eur J Immunol. 1996;26:2758-63.

51. Frei K, Nohava K, Malipiero UV, Schwerdel C, Fontana A. Production of macrophage colony-stimulating factor by astrocytes and brain macrophages. J Neuroimmunol. 1992;40:189-95.

52. Tyor WR, Glass JD, Griffin JW, Becker PS, MCArthur JC, Bezman L, et al. Cytokine expression in the brain during the acquired immunodeficiency syndrome. Ann Neurol. 1992;31:349-60.
53. Nuovo GJ, Gallery F, MacConnell P, Braun A. In situ detection of polymerase chain reaction-amplified HIV-1 nucleic acids and tumor necrosis factor-alpha RNA in the central nervous system. Am J Pathol. 1994;144:659-66.

54. Persidsky Y, Buttini M, Limoges J, Bock P, Gendelman HE. An analysis of HIV-1-associated inflammatory products in brain tissue of humans and SCID mice with HIV-1 encephalitis. J Neurovirol. 1997:3:401-16.

55. Nandi S, Gokhan S, Dai XM, Wei S, Enikolopov G, Lin H, et al. The CSF-1 receptor ligands IL-34 and CSF-1 exhibit distinct developmental brain expression patterns and regulate neural progenitor cell maintenance and maturation. Dev Biol. 2012;367:100-13.

56. Wang Y, Szretter KJ, Vermi W, Gilfillan S, Rossini C, Cella M, et al. IL-34 is a tissue-restricted ligand of CSF1R required for the development of Langerhans cells and microglia. Nat Immunol. 2012;13:753-60.

57. Luo J, Elwood F, Britschgi M, Villeda S, Zhang H, Ding Z, et al. Colony-stimulating factor 1 receptor (CSF1R) signaling in injured neurons facilitates protection and survival. J Exp Med. 2013;210:157-72.

58. Ma D, Doi $Y$, Jin S, Li E, Sonobe $Y$, Takeuchi $H$, et al. TGF-beta induced by interleukin-34-stimulated microglia regulates microglial proliferation and attenuates oligomeric amyloid beta neurotoxicity. Neurosci Lett. 2012;529:86-91.

59. Wei S, Nandi S, Chitu V, Yeung YG, Yu W, Huang M, et al. Functional overlap but differential expression of CSF-1 and IL-34 in their CSF-1 receptormediated regulation of myeloid cells. J Leukoc Biol. 2010;88:495-505.

60. Wang Y, Berezovska O, Fedoroff S. Expression of colony stimulating factor- 1 receptor (CSF-1R) by CNS neurons in mice. J Neurosci Res. 1999;57:616-32.

61. Sawada M, Itoh Y, Suzumura A, Marunouchi T. Expression of cytokine receptors in cultured neuronal and glial cells. Neurosci Lett. 1993;160:131-4.

62. Sherr CJ, Rettenmier CW, Sacca R, Roussel MF, Look AT, Stanley ER. The $\mathrm{C}$-fms proto-oncogene product is related to the receptor for the mononuclear phagocyte growth factor, CSF-1. Cell. 1985;41:665-76.

63. Barve RA, Zack MD, Weiss D, Song RH, Beidler D, Head RD. Transcriptional profiling and pathway analysis of CSF-1 and IL-34 effects on human monocyte differentiation. Cytokine. 2013;63:10-7.

\section{Submit your next manuscript to BioMed Central and take full advantage of:}

- Convenient online submission

- Thorough peer review

- No space constraints or color figure charges

- Immediate publication on acceptance

- Inclusion in PubMed, CAS, Scopus and Google Scholar

- Research which is freely available for redistribution 